\title{
Horta orgânica de ervas medicinais: inclusão social na comunidade da Barra em Muriaé/MG - Brasil
}

José Luiz de Freitas Paixão ${ }^{1}$

Dráuzio Humberto ${ }^{2}$

José Emílio Zanzirolani de Oliveira ${ }^{3}$

\section{Resumo}

A implantação de uma horta orgânica de ervas medicinais teve como objetivo a inclusão social de pessoas carentes na comunidade da Barra (Muriaé/MG) ao permitir acesso a tratamento de doenças por meio da fitoterapia. Inicialmente, houve a escolha das espécies, a obtenção de mudas e a instalação da horta. As 40 espécies selecionadas, sob manejo agroecológico, eram indicadas como terapêuticas aos 25 principais problemas de saúde levantados na comunidade. 0 formato didático da horta, representando o corpo humano, serviu como referência às indicações de uso de cada espécie. A comunidade foi envolvida no projeto desde o início, forneceu matrizes e colheu as ervas medicinais. O processamento pós-colheita, o preparo de fitoterápicos e a dispensação dos fitoterápicos ocorriam nas dependências da Paróquia local. As formas fitoterápicas disponibilizadas são de uso interno (erva seca, tintura, xarope) e tópico (creme, gel, pomada), sendo as mais procuradas: gel, tintura e xarope. O sucesso do projeto se refletiu no aumento do número de espécies utilizadas, passando de 40 espécies em 2006 para 170 espécies em 2012, dentre elas: alecrim de jardim (Rosmarinus officinalis), alfavaca (Ocimum basilicum), amora (Morus alba), arnica brasileira (Solidago microg/ossa), calêndula (Calendula officinalis), camomila (Matricaria chamomilla), capim gordura (Melinis minutiflora), cavalinha (Equisetum arvense), chapéu-de-couro (Echinodorus grandiflorus) e espinheira santa (Maytenus aquifolium). A produção orgânica de ervas medicinais permitiu a inclusão social de pessoas carentes através de 32.400 atendimentos entre 2006 e 2012, uma média de 385 pessoas/mês.

Palavras-chave: Plantas medicinais. Fitoterapia. Agroecologia. Inclusão social.

\section{Introdução}

A agroecologia, na busca de agroecossistemas sustentáveis, procura estabelecer a base científica de uma agricultura que depende menos de insumos externos à unidade de produção agrícola e que conserva os recursos naturais. Nos sistemas agroecológicos, a reciclagem de energia e nutrientes é maximizada como forma de evitar a perda destes recursos durante os processos produtivos (AQUINO; ASSIS, 2007). Assim, a produção sustentável deriva do equilíbrio entre os componentes bióticos e abióticos coexistentes e permanece pelo manejo e pela tolerância (a estresses e a adversidades) (ALTIERI, 2004). Sistemas de produção de base agroecológica caracterizam-se pela utilização de tec-

\footnotetext{
1 Biólogo, mestre, Instituto Federal de Educação, Ciência e Tecnologia Sudeste de MG, campus Muriaé (IFMURIAÉ). Avenida Monteiro de Castro, 550 - Bairro Barra - 36880-000, Muriaé, Minas Gerais (BR). jose.paixao@ifsudestemg.edu.br

2 Paróquia de Nossa Senhora da Conceição - Rua Lincoln Marinho, s/n Barra - CEP: 36.880-000, Muriaé, Minas Gerais (BR)

3 Biólogo, doutor, Instituto Federal de Educação, Ciência e Tecnologia Sudeste de MG, campus Barbacena (IFBARBACENA). Rua Monsenhor José Augusto, 204 - Bairro São José - 36205-018, Barbacena, Minas Gerais (BR). jose.oliveira@ifsudestemg.edu.br
} 
nologias que respeitem a natureza, mantendo ou alterando pouco as condições de equilíbrio entre os organismos participantes do processo de produção. Com base nesses princípios, foram desenvolvidos diferentes estilos de agricultura não industrial. Entre esses, a agricultura orgânica tem sido a mais difundida, e foi reconhecida junto ao mercado como sinônimo de todas as outras (ASSIS; ROMEIRO, 2002).

De acordo com Caporal e Costabeber (2000), a busca da qualidade de vida permeia as novas combinações tecnológicas, sociais e éticas que permitem a produção e o consumo de alimentos com qualidade biológica superior, livres de insumos tóxicos no processo produtivo. Os autores consideram essa a Dimensão Social da agroecologia. Quando se referem à Dimensão Cultural da agroecologia, enfatizam que as intervenções devem respeitar a cultura local, pois os saberes e os valores da população precisam ser analisados, compreendidos e utilizados como ponto de partida dos processos de desenvolvimento que devem espelhar a "identidade cultural" das pessoas que vivem e trabalham em dado agroecossistema. As duas dimensões devem ser congregadas como prática realizada por sujeitos que se caracterizam pela forma particular de relacionamento com o meio ambiente.

Uma ação do governo que contempla a inclusão social, a igualdade e o combate à pobreza foi o PAC-Saúde, lançado em fevereiro de 2008 com a denominação Mais Saúde. Este programa sinaliza a vinculação da saúde com o desenvolvimento da sociedade (MENICUCCI, 2009). Essa iniciativa usa a fitoterapia para inserir as plantas medicinais na saúde pública - uma contribuição efetiva à saúde da população (KLEIN et al., 2009). Os fitoterápicos são medicamentos oriundos da biodiversidade, representam uma fonte renovável de inovação no campo da saúde e contribuem com a melhoria de vida da população, tanto por meio da assistência farmacêutica, quanto pela inclusão social, no contexto da Política Nacional de Plantas Medicinais e Fitoterápicos (BRASIL, 2011).

O emprego terapêutico de plantas medicinais e produtos fitoterápicos no Brasil vem se consolidando nos últimos tempos. Desde 1983, uma referência para implantação de hortas orgânicas de plantas medicinais é o projeto "Farmácia Viva", desenvolvido pela Universidade Federal do Ceará (MATOS, 1998; MARQUES et al., 2012). Essas hortas padronizadas e instaladas em comunidades organizadas seguem as normas da agricultura orgânica. O trabalho tem característica social com finalidade de oferecer, sem fins lucrativos, assistência farmacêutica fitoterápica de base científica às comunidades (OLIVEIRA et al., 2013). Essa assistência funciona como coadjuvante da atenção primária à saúde e emprega plantas de ocorrência local e regional, cultivadas e espontâneas, dotadas de atividade terapêutica comprovada (MATOS, 1998; LORENZI; MATOS, 2002; SIMÕES et al., 2004; ARNOUS; SANTOS; BEINNER, 2005; OLIVEIRA et al., 2013). Uma das ferramentas auxiliares na escolha dos fitoterápicos foi o método biodigital (ROSÁRIO-UBÁ; OLIVEIRA; ARRUDA, 2011).

Segundo Silva Júnior (1997) e Arnous, Santos e Beinner (2005), o avanço da medicina convencional não inibiu o progresso das práticas curativas populares, pois estas trazem uma melhor relação custo/beneficio à população e promovem a saúde a partir de plantas medicinais obtidas localmente. Apesar da intensa substituição das plantas medicinais por medicamentos industrializados, o interesse pelo cultivo dessas plantas tem aumentado devido à busca de uma vida mais saudável e de uma forma de tratamento curativo mais natural, adicionado ao fácil acesso e o baixo custo.

No contexto global, a Organização Mundial de Saúde (OMS) reconhece que 80\% da população dos países em desenvolvimento utiliza práticas tradicionais nos cuidados básicos de saúde e, deste universo, $85 \%$ utilizam preparados vegetais. Nesse sentido, a OMS recomenda a difusão mundial dos conhecimentos necessários ao uso racional das plantas medicinais e medicamentos fitoterápicos.

O Brasil tem ampla tradição de uso das plantas medicinais e tem tecnologia para validar cientificamente este conhecimento (BRASIL, 2011). No nosso país, o conhecimento acerca das plantas medicinais é uma rica mistura de conhecimento dos indígenas, dos europeus e dos africanos a respeito de espécies tropicais e exóticas aclimatadas desde a colonização. É indiscutível a necessidade de resgatar o conhecimento empírico a respeito da utilização das plantas medicinais no tratamento de 
inúmeras doenças, já que essa prática representa um dos principais recursos terapêuticos de muitas comunidades e de muitos grupos étnicos (MARTINS et al., 2003; ARNOUS; SANTOS; BEINNER, 2005; OLIVEIRA, 2008).

Segundo Matos (1998) e Simões et al. (2004), a implantação de projetos de uso de plantas medicinais é de grande importância por aceitar a premissa de que nunca se deve subestimar a sabedoria popular acerca das plantas medicinais. O conhecimento popular pode ser repassado como verdade científica depois de ter comprovado e assegurado a sua pertinência através de testes farmacológicos.

As espécies medicinais produzem componentes farmacologicamente ativos por influência qualitativa e quantitativa de fatores genéticos, edáficos e fitotécnicos. Enfocando o último fator, tem-se as variações contidas no plantio, adubação, tratos culturais, colheita e pós-colheita (OLIVEIRA, 2008; MEIRA, SOUZA, MARTINS, 2010). Estudos confirmam que a utilização de adubos químicos, dentro dos limites técnicos, não causa prejuízo às plantas, porém, altera a qualidade química dos compostos secundários (CORREA JÚNIOR; MING; SCHEFFER, 1996; HOFFMANN et al., 2001; MAY et al., 2008). Mesmo que observaram diferenças significativas em relação ao rendimento de óleo essencial em Capim-Santo não tenham sido observadas em experimentos, Carvalho et al. (2005) observaram maior produtividade e menor custo de produção quando utilizada a adubação orgânica. Sendo assim, a prática agroecológica é preferível para cultivar ervas medicinais (MARTINS et al., 2003).

Considerando o espaço disponível ao cultivo, a demanda social por tratamento de saúde e a aceitação da fitoterapia pela comunidade, a pesquisa em Muriaé-MG se orientou para revelar a prática agroecológica e a inclusão social promovida pelo cultivo das plantas medicinais.

\section{Material e Métodos}

As atividades foram iniciadas em janeiro de 2006, com a instalação da horta orgânica de ervas medicinais e a unidade de secagem e de processamento de ervas. A horta foi instalada em área de aproximadamente $2000 \mathrm{~m}^{2}$, circundada por drenos a céu aberto, nas dependências do Centro Educacional Dom Delfim, no Bairro Barra, Muriaé-MG. Com fins didáticos, uma parte da horta foi delimitada por garrafas "pet" de refrigerantes (capacidade de dois litros, preenchidas por água visando conferir resistência às mesmas), configurando o formato externo do corpo humano. Cada região desse "corpo humano", correspondente a um sistema/órgão, recebeu um canteiro com plantas medicinais relacionadas ao tratamento de problemas de saúde daquele sistema/órgão. Assim, na região da cabeça, por exemplo, havia ervas indicadas para o sistema nervoso e para a memória. Outra parte da horta foi ocupada com outros canteiros em formato tradicional. Muitas ervas medicinais que surgiram espontaneamente na horta foram mantidas. Uma área foi destinada à manutenção de plantas matrizes adquiridas sobretudo na comunidade. Foi separada uma área para produzir composto orgânico a partir das folhas oriundas da varrição do pátio do Centro Educacional, do esterco bovino doado pela comunidade e do material vegetal oriundo da própria horta e dos arredores. As medas foram construídas seguindo a proporção de $20 \mathrm{~cm}$ de material vegetal (oriundo da limpeza da área) e $5 \mathrm{~cm}$ de esterco bovino.

No preparo dos canteiros, utilizou-se substrato contendo composto orgânico, produzido no local e solo do próprio local (latossolo vermelho amarelo), respectivamente na proporção de uma parte do composto e duas partes de solo. Os canteiros receberam cobertura morta de folhas advindas da varrição do pátio da escola. 0 procedimento realizado visou manter o solo com cobertura viva ou morta, protegendo-o da incidência direta do sol. O manejo fitossanitário foi principalmente preventivo, com a manutenção de quebra-ventos, plantas companheiras, hospedeiras, atrativas e repelentes, com o objetivo de proteger as ervas medicinais de herbívoros e organismos patogênicos. 
Antes da implantação da horta, foi feito o levantamento dos principais problemas de saúde da comunidade e que poderiam ser tratados com plantas medicinais. Utilizaram-se como fonte de dados os problemas tratados pelos medicamentos dispensados na farmácia de dispensação de medicamentos alopáticos, da Paróquia de Nossa Senhora da Conceição da Barra, que eram doados à população, sob a supervisão de um farmacêutico voluntário. Em seguida, foi realizada consulta em bibliografia sobre plantas medicinais como Correa Júnior, Ming e Scheffer (1996), Lorenzi e Matos (2002) e Martins et al. (2003), trabalhos científicos disponíveis em sítios da internet e anotação das espécies com indicação terapêutica adequada e comprovada. A partir da correlação entre os problemas levantados e as plantas medicinais utilizáveis, foi feita a seleção das espécies a serem cultivadas na horta. A pesquisa realizada em 2006 encontrou 25 problemas de saúde relacionados aos sistemas nervoso (como depressão), respiratório (como gripe e asma), digestório (como azia, úlcera e fígado), circulatório (como pressão alta e hemorróidas), urinário (como cálculo renal), locomotor (como artrite e artrose), dentre outros.

Esses problemas, ao serem revisados na literatura especializada (SILVA JÚNIOR, 1997; LORENZI; MATOS, 2002; MARTINS et al., 2003), permitiram selecionar 40 espécies medicinais recomendadas aos problemas identificados. Com a lista de plantas medicinais, verificaram-se quais estariam adaptadas ao clima e disponíveis ao cultivo, sendo obtidas no município de Muriaé, principalmente em quintais. Os propágulos coletados serviram a duas finalidades: identificação específica e propagação. A identificação foi realizada por consulta a literaturas especializadas, chaves dicotômicas e especialistas. Dessas, realizou-se o fichamento sobre modos de identificação e de emprego das espécies selecionadas, norteado em literatura como Silva Júnior (1997), Lorenzi e Matos (2002), Martins et al. (2003) e acervos digitais de periódicos e herbários em sítios na internet. As espécies identificadas foram reproduzidas por sementes e estacas visando à obtenção de mudas, que foram inseridas na área de cultivo.

Após o crescimento adequado das espécies, foi iniciada, com auxílio da comunidade, a colheita em horário próximo às nove horas da manhã, após intervalo de pelo menos três dias sem chuva e sem estar nublado (MARTINS et al., 2003). O material coletado foi conduzido à área de processamento pós-colheita, onde foram realizados procedimentos de assepsia e onde o material foi posto para secar. As salas de secagem e manipulação foram instaladas em área anexa à Paróquia de Nossa Senhora da Conceição, no Bairro Barra (Muriaé/MG). A sala de secagem, toda forrada com placas de isopor, foi equipada com desumidificador de ambiente e prateleiras de madeira. A armazenagem foi feita em sacolas de papel Kraft, envolvidas por polietileno, conforme recomendação de Arruda (2004). As condições sanitárias do material armazenado foram avaliadas periodicamente. A sala de manipulação foi equipada com balanças de precisão, vidrarias, mesa, prateleira e caixas de papelão destinadas ao acondicionamento das ervas secas e embaladas. A partir das primeiras colheitas, houve a instalação, em outra sala cedida pela Paróquia, de uma farmácia de dispensação de plantas secas e fitoterápicos. 0 processo foi realizado pela equipe supervisionada por um farmacêutico responsável.

0 acervo de espécies utilizadas foi aumentando gradativamente e chegou a cerca de 170 espécies em 2011. Este fato gerou a necessidade de um local que permitisse aumentar a produção e aprofundar as práticas agroecológicas. Isso motivou, a partir de dezembro de 2012, a realocação da horta para um espaço adequado no IFMURIAÉ. Essa horta, mantida desde então no Bairro Sofoco, é cuidada pelos funcionários dessa instituição e serve como laboratório ao Curso Técnico em Agroecologia do IFMURIAÉ. 


\section{Resultados e Discussão}

Os problemas de saúde, identificados pelo levantamento na comunidade do Bairro Barra em Muriaé/MG, foram organizados e os de maior ocorrência serviram à seleção das espécies medicinais a serem cultivadas na Horta de Plantas Medicinais (Tabela 1).

Tabela 1. Relação de 40 espécies medicinais (nomes populares e científicos) e as indicações de uso nos principais problemas levantados no Bairro Barra. Muriaé-MG, 2006.

\begin{tabular}{|c|c|c|}
\hline Nome Popular & Nome Científico & Indicações de uso \\
\hline Alcachofra & Cynara scolymus & Fígado, vesícula biliar \\
\hline Alecrim de jardim & Rosmarinus officinalis & Hemorróidas \\
\hline Alecrim do campo & Baccharis dracunculifolia & Garganta, gripe \\
\hline Arnica brasileira & Solidago microglossa & Artrite \\
\hline Arnica do mato & Chaptalia nutans & Artrite, artrose, reumatismo \\
\hline Assa peixe & Vernonia polyanthes & Expectorante, tosse \\
\hline Azedinha & Oxalis latifolia & Azia, gastrite \\
\hline Boldo & Vernonia condensata & Fígado \\
\hline Boldo peludo & Plectranthus barbatus & Fígado \\
\hline Boldo rasteiro & Plectranthus ornatus & Fígado \\
\hline Cambará & Lantana camara & Bronquite, expectorante, tosse \\
\hline Cana de macaco & Costus spiralis & Gota, rins \\
\hline Cânfora & Artemisia camphorata & Artrite, reumatismo \\
\hline Capim cidreira & Cymbopogom citratus & Pressão alta, sistema nervoso \\
\hline Capuchinha & Tropaeolum majus & Gripe \\
\hline Carqueja & Baccharis trimera & Fígado, gota, rins, triglicérides \\
\hline Cipó cabeludo & Mikania cordifolia & Doenças renais, ácido úrico \\
\hline Cipó mil homens & Aristolochia triangularis & Gripe \\
\hline Cordão de frade & Leonotis nepetaefolia & Ácido úrico, asma, rins \\
\hline Dente de leão & Taraxacum officinale & Fígado \\
\hline Erva macaé & Leonurus sibiricus & Fígado \\
\hline Espinheira santa & Maytenus aquifolium & Úlcera gastroduodenal \\
\hline Gervão & Starchytapheta cayennensis & Gripe \\
\hline Guaco & Mikania glomerata & Bronquite, expectorante, tosse \\
\hline Hortelã & Mentha $x$ villosa & Vermes \\
\hline Jambolão & Syzygium jambolanum & Diabetes \\
\hline Macela & Achyroclyne satureioides & Sistema nervoso \\
\hline Melão de são caetano & Momordica charantia & Vermes \\
\hline Mentrasto & Ageratum conyzoides & Depressão \\
\hline Mil folhas & Achillea millefolium & Artrose \\
\hline Pé de galinha & Eleunice indica & Gripe \\
\hline Penicilina & Alternanthera brasiliana & Garganta, gripe \\
\hline Picão & Bidens pilosa & Fígado, rins \\
\hline Pulmonária & Stachys byzantina & Expectorante, tosse \\
\hline Quebra pedra & Phyllanthus niruri & Ácido úrico, rins \\
\hline Sabugueiro & Sambucus australis & Gripe \\
\hline Salsão & Apium graveolens & Gripe \\
\hline Tanchagem & Plantago major & Garganta, gripe \\
\hline Tiririca & Cyperus rotundus & Vermes \\
\hline Tuia & Thuja orientalis & Gripe \\
\hline
\end{tabular}

Fonte: Elaboração própria, exceto a coluna "Indicações de uso", que foi adaptada de Silva Júnior (1997), Lorenzi e Matos (2002) e Martins et al. (2003). 
Essa diversidade de espécies medicinais, desde herbáceas (hortelã - Mentha x villosa) a arbóreas (jambolão - Syzygium jambolanum), permite perceber a disponibilidade ampla de material e a ocupação de variados estratos. Dessas espécies, destacam-se as plantas nativas, como assa peixe (Vernonia polyanthes), carqueja (Baccharis trimera) e cipó cabeludo (Mikania cordifolia); e as exóticas, como alecrim de jardim (Rosmarinus officinalis), boldo peludo (Plectranthus barbatus) e capim cidreira (Cymbopogom citratus).

A forma didática em que foi implantada a horta orgânica de plantas medicinais (Figura 1) colaborou para disseminar os conhecimentos sobre as ervas e suas propriedades curativas e para manter esse saber na comunidade.

Figura 1. Horta orgânica de plantas medicinais no Centro Educacional Dom Delfim, no Bairro Barra (Muriaé-MG, 2006): à esquerda o canteiro didático delimitado por garrafas "pet" visualizando, em primeiro plano, a cabeça do ser humano e à direita visualizando os pés. Muriaré-MG, 2006.
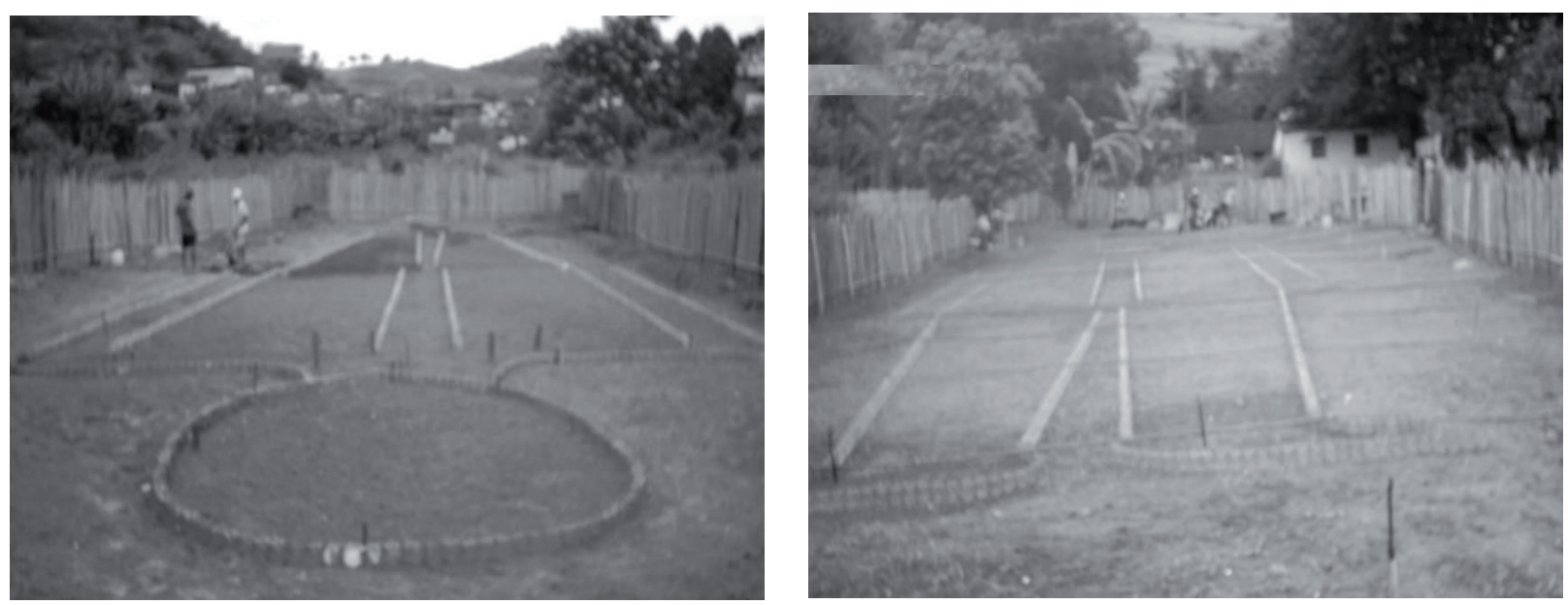

Fonte: Elaboração própria.

Foi adotada a adubação orgânica dos canteiros porque ela é agroecológica e está de acordo com os modos de cultivo das plantas medicinais (CORREA JÚNIOR; MING; SCHEFFER, 1996; HOFFMANN et al., 2001; MAY et al., 2008). As plantas espontâneas que surgiram na horta foram mantidas por servirem como quebra ventos (Figura 2), como matéria prima vegetal destinada ao preparo de alguns fitoterápicos e por contribuírem com o aumento da biodiversidade. Essa estratégia permitiu bons níveis de equilíbrio ecológico na área, diminuindo os problemas fitossanitários e aumentando os níveis de sustentabilidade. Tal estratégia está de acordo com Altieri (2004).

A produção de ervas medicinais seguiu os princípios agroecológicos, utilizando insumos internos, como as folhas oriundas da varrição do pátio do Centro Educacional que serviram para elaborar o composto orgânico, este último utilizado como substrato nos canteiros. Esse fato está de acordo com as afirmações de Aquino e Assis (2007), para os quais, nos sistemas agroecológicos, a reciclagem de energia e nutrientes é maximizada como forma de evitar a perda destes recursos durante os processos produtivos. 
Figura 2. Horta orgânica de plantas medicinais no Centro Educacional Dom Delfim, no Bairro Barra (Muriaé-MG, 2006): plantas espontâneas e cultivadas; nas laterais percebe-se as plantas com função de quebra vento. Muriaré-MG, 2006.

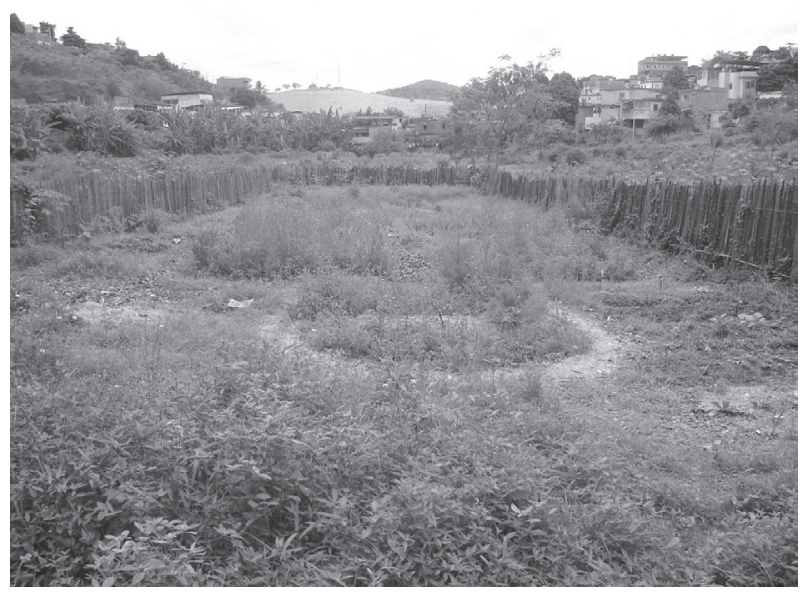

Fonte: Elaboração própria.

As plantas serviram à elaboração de formas farmacêuticas dispensadas como ervas secas, creme, gel, pomada, tintura e xarope. As formas mais procuradas foram gel, tintura e xarope e serviram à população que as utilizam no tratamento de problemas (Tabela 2).

Tabela 2. Principal demanda popular de tratamento fitoterápico na farmácia de dispensação de plantas secas e fitoterápicos da Paróquia de Nossa Senhora da Conceição entre 2006 e 2012 . Muriaé-MG, 2012.

\begin{tabular}{cc}
\hline Problema de saúde & Plantas recomendadas (citadas pelo nome popular) \\
\hline Amigdalite & angico vermelho, anis estrelado, romã, tanchagem \\
Dores musculares & arnica brasileira, arnica do mato, cânfora, mil folhas \\
Gripe & alfavaca, assa-peixe, calêndula, cambará, eucalipto, guaco \\
Menopausa & Amora \\
\hline
\end{tabular}

Fonte: Elaboração própria.

Desde a implantação do projeto, em 2006, 32.400 pessoas procuraram a farmácia de dispensação de plantas secas e fitoterápicos em busca de preparados fitoterápicos e ou plantas secas, ou seja, uma média aproximada de 4630 pessoas/ano e 385 pessoas/mês. A expectativa inicial foi atender cerca de 1800 pessoas/ano (média de 150 pessoas/mês), de ambos os sexos, sem distinção de raça e idade. Assim, superou em 2,5 vezes a expectativa inicial do projeto, o que está de acordo com o relato de Silva et al. (2011), quando afirmam que o interesse pelo cultivo das plantas medicinais tem aumentado "devido à busca de uma vida mais saudável e de uma forma de tratamento curativo mais natural, adicionado ao fácil acesso e ao baixo custo".

O trabalho pode ser considerado como uma "farmácia viva", conforme foi concebido por Matos (1998), pois "tem características de um programa de medicina social cuja adoção tem por finalidade oferecer, sem fins lucrativos, assistência farmacêutica fitoterápica de base científica, às comunidades como coadjuvante à atenção primária de saúde". Isso foi feito pelo aproveitamento de plantas de ocorrência local ou regional, cultivadas ou espontâneas, dotadas de atividade terapêutica compro- 
vada". O local de dispensação dos fitoterápicos (Figura 3) é de fácil acesso ao público, seja pela localização da Paróquia, seja pelos horários de funcionamento.

Figura 3. Vista parcial da farmácia de dispensação de plantas secas e fitoterápicos da Paróquia de Nossa Senhora da Conceição entre 2002 e 2012: área de armazenamento e dispensação. Muriaé-MG, 2012.

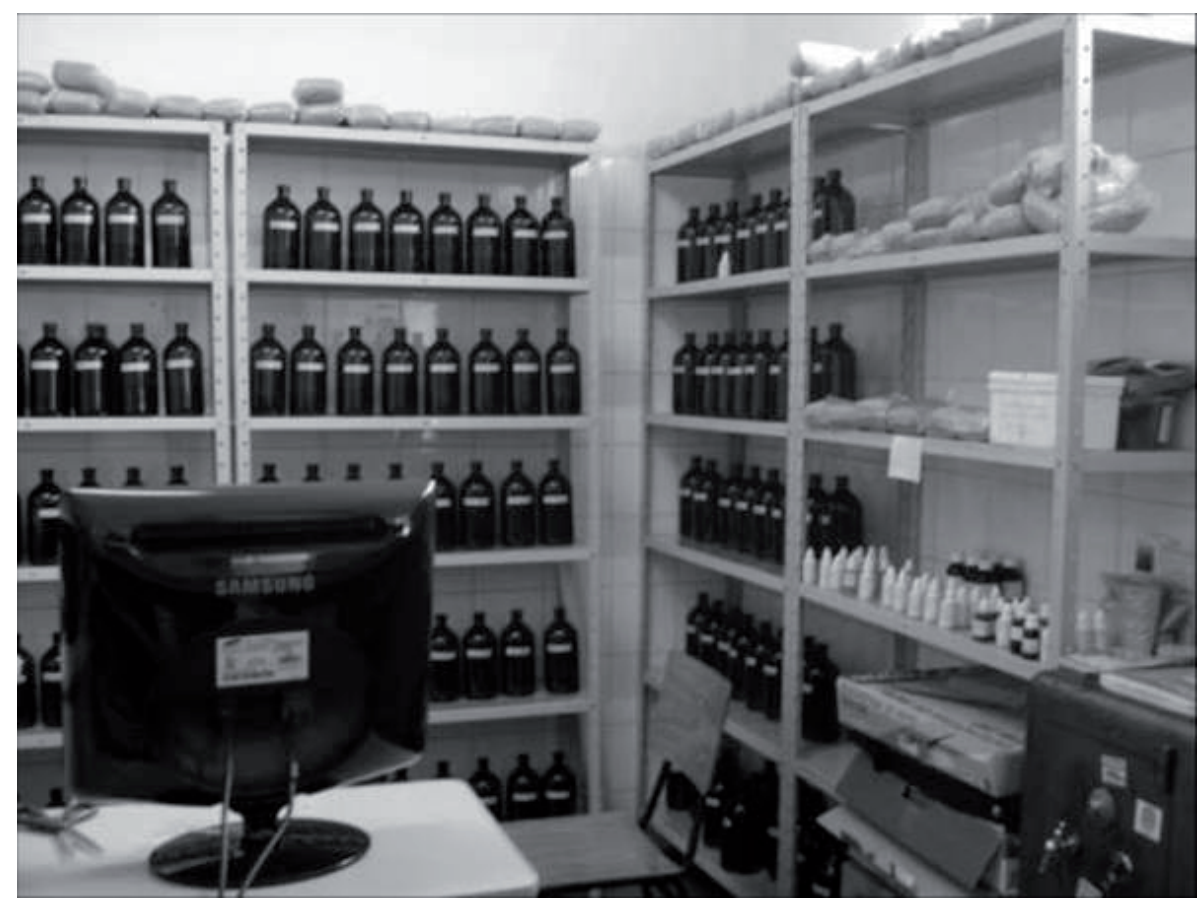

Fonte: Elaboração própria.

O trabalho realizado em Muriaé desde 2006 tem consonância com o proposto pela Organização Mundial de Saúde (1991). A OMS propõe a promoção do retorno às práticas populares em saúde, dentre as quais as plantas medicinais. O trabalho também corresponde à atualidade no Brasil, evidenciada pela "Política Nacional de Plantas Medicinais e Fitoterápicos" (BRASIL, 2006) e pelo "Programa Nacional de Plantas Medicinais e Fitoterápicos" propostos pelo Ministério da Saúde (BRASIL, 2009), citados, em parte, a seguir: "O governo federal aprovou a Política Nacional de Plantas Medicinais e Fitoterápicos, por meio do Decreto n 5.813, de 22 de junho de 2006, a qual se constitui em parte essencial das políticas públicas de saúde, meio ambiente, desenvolvimento econômico e social como um dos elementos fundamentais de transversalidade na implementação de ações capazes de promover melhorias na qualidade de vida da população brasileira".

A política nacional de plantas medicinais e fitoterápicos destaca a necessidade de realizar trabalhos que permitam o uso adequado de plantas medicinais e fitoterápicos, tendo como atividades: "sistematizar demandas de pesquisas em toda a cadeia produtiva de plantas medicinais e fitoterápicos; fomentar pesquisas agroecológicas; incentivar e fomentar a pesquisa de plantas medicinais para aplicações terapêuticas" (BRASIL, 2006, 2009; MINISTÉRIO DO DESENVOLVIMENTO AGRÁRIO, 2012).

Finalmente, o trabalho se mostrou sustentável desde sua implantação, pois utilizou recursos internos na produção, na manutenção e no envolvimento com a comunidade. Essa forma é coerente com os princípios da agroecologia (CAPORAL; COSTABEBER, 2000), por ter sustentabilidade nas dimensões cultural e social. 


\title{
4 Conclusões
}

As plantas medicinais úteis à comunidade da Barra, em Muriaé/MG, foram selecionadas e serviram à implantação e manutenção de uma horta agroecológica. Os vegetais obtidos contribuíram para a inclusão social de pessoas carentes porque permitiram o tratamento de problemas de saúde através da fitoterapia. Pelo número de pessoas que buscaram a farmácia de dispensação de plantas secas e fitoterápicos, de 2006 a 2012, média de 385 pessoas/mês, tem-se o indicativo de que este trabalho faz parte da vida da comunidade e representa uma opção terapêutica de qualidade, que cumpre o objetivo da horta construída em bases agroecológicas.

\section{Organic garden of medicinal herbs: social inclusion in community of Barra in Muriaé/MG - Brazil}

\begin{abstract}
The implantation of an organic garden of medicinal herbs had as objective at social inclusion of poor people in the community of Barra (Muriaé / MG) to permit access to treatment of diseases through herbal medicine. Initially there was the selection of the species, obtaining seedlings and installation of the garden. The 40 selected species under agroecological management, were indicated as therapy to 25 major health problems raised in the community. The didactic format of the garden, representing the human body, served as a reference to the indications for use of each species. The community was involved in the project from the start, being active in providing matrices and harvesting of medicinal herbs. The post-harvest processing, preparation and dispensation of the of phytotherapics occurred in dependencies of the local parish. The forms are available herbal internal use (dried herb, tincture, syrup) and topical (cream, gel, ointment), being the most searched: gel, tincture and syrup. The success of this project is reflected in the increasing number of species used, from 40 species in 2006 to 170 species in 2012, including: garden rosemary (Rosmarinus officinalis), basil (Ocimum basilicum), mulberry (Morus alba), arnica Brazilian (Solidago microglossa), calendula (Calendula officinalis), chamomile (Matricaria chamomilla), grass (Melinis minutiflora), horsetail (Equisetum arvense), hat-in-leather (Echinodorus grandiflorus) and espinheira santa (Maytenus aquifolium). Organic production of medicinal herbs, from 2006 to 2012, allowed the social inclusion of poor people, counted by 32,400 attendances, an average of 385 people / month.
\end{abstract}

Keywords: Medicinal plants. Phytotherapy. Agroecology. Social inclusion.

\section{Referências bibliográficas}

ALTIERI, M. Agroecologia: a dinâmica produtiva da agricultura sustentável. 4 ed. Porto Alegre: Editora UFRGS, 2004.

AQUINO, A.M.; ASSIS, R.L. Agricultura orgânica em áreas urbanas e periurbanas com base na agroecologia. Ambiente \& Sociedade, Campinas v. X, n.1, p.137-150, jan./jun. 2007.

ARNOUS, A.H.; SANTOS, A.S.; BEINNER, R.P.C. Plantas medicinais de uso caseiro-conhecimento popular e interesse por cultivo comunitário. Revista Espaço para a Saúde, Londrina, v.6, n.2, p.16. 2005. 
ARRUDA, V.M. Colheita, pós-colheita e comercialização de plantas medicinais. Ação Ambiental, Viçosa, ano 7, n. 28, p.21-23, 2004.

ASSIS, R.L.; ROMEIRO, A.R. Agroecologia e agricultura orgânica: controvérsias e tendências.

Desenvolvimento e Meio Ambiente, Curitiba, v.6, p.67-80, 2002.

BRASIL. Ministério da Saúde. Secretaria de Ciência, Tecnologia e Insumos Estratégicos. Inovação em temas estratégicos de saúde pública. Ministério da Saúde. Brasília: Ministério da Saúde, 2011.

BRASIL. Ministério da Saúde, Secretaria de Ciência, Tecnologia e Insumos Estratégicos, Departamento de Assistência Farmacêutica. Política nacional de plantas medicinais e fitoterápicos. Brasília: Ministério da Saúde, 2006. 60p. - (Série B. Textos Básicos de Saúde)

BRASIL. Ministério da Saúde, Secretaria de Ciência, Tecnologia e Insumos Estratégicos, Departamento de Assistência Farmacêutica e Insumos Estratégicos. Programa Nacional de Plantas Medicinais e Fitoterápicos. Brasília: Ministério da Saúde, 2009. 136 p.

CAPORAL, F.R.; COSTABEBER, J.A. Agroecologia e desenvolvimento rural sustentável: perspectivas para uma nova extensão rural. Agroecologia e Desenvolvimento Rural Sustentável, Porto Alegre, v.1, n.1, p. 16-37, 2000.

CARVALHO, C.M. et al. Rendimento da produção de óleo essencial de capim-santo submetido a diferentes tipos de adubação. Revista de Biologia e Ciências da Terra, Campina Grande, v. 5, n. 2, p. ?-x?, jul./dez. 2005. Disponível em: <http://eduep.uepb.edu.br/rbct/sumarios/pdf/capimsanto. pdf $>$. Acesso em: 20 mai. 2013.

CORREA JÚNIOR, C.; MING, L.C.; SCHEFFER, M.C. Cultivo de plantas medicinais, condimentares e aromáticas. 2 ed. Jaboticabal: FUNDEP, 1996. 151p.

HOFFMANN, I. et al. Farmers management strategies to maintain soil fertility in a remote area in northwest Nigeria. Agriculture, Ecosystems and Environment, v. 86, n. 3, p. 263-275, 2001. Disponível em: <http://www.sciencedirect.com/science/article/pii/S0167880900002887>. Acesso em: 20 mai. 2013.

KLEIN, T. et al. Fitoterápicos: um mercado promissor. Revista de Ciências Farmacêuticas Básica e Aplicada, Araraquara, v. 30, n. 3, p.241-248, 2009.

LORENZI, H.; MATOS, F. J. A. Plantas medicinais no Brasil: nativas e exóticas cultivadas. Nova Odessa: Instituto Plantarum, 2002.

MARQUES, G. S. et al. Caracterização fitoquímica e físico-química das folhas de Bauhinia forficata coletada em duas regiões brasileiras. Revista de Ciências Farmacêuticas Básica e Aplicada, Araraquara, v. 33, n. 1, p. 57-62, 2012.

MARTINS, E. R. et al. Plantas medicinais. Viçosa, MG: UFV, 2003.

MATOS, F.J.A. Farmácias vivas. Fortaleza: Edições UFC. 1998.

MAY, A. et al. Produtividade da biomassa de melissa em função de intervalo de cortes e doses de nitrogênio. Horticultura Brasileira, Brasília, v. 26, n. 3, p. 312-315, 2008. 
MINISTÉRIO DO DESENVOLVIMENTO AGRÁRIO. Plantas Medicinais e Fitoterápicos. Disponível em: <www.mda.gov.br/portal/saf/programas/div/2294038>. Acesso em: 25 set. 2012.

MEIRA, M.R.; SOUZA, S.A.M.; MARTINS, E.R. Plantas medicinais: produção e cultivo da Melissa officinalis no Brasil. 2010. Disponível em: < http://www.conhecer.org.br/enciclop/2010b/plantas>. Acesso em: 03 dez. 2012.

MENICUCCI, T. M. G. O Sistema Único de Saúde, 20 anos: balanço e perspectivas. Caderno de Saúde Pública, Rio de Janeiro, v. 25, n. 7, p. 1620-1625, jul. 2009. Disponível em: <www. scielosp.org/pdf/csp/v25n7/21.pdf>. Acesso em: 05 nov. 2012.

OLIVEIRA, J.E.Z. Plantas medicinais: tratos culturais e emprego. 2 ed. Ubá: ECINE-UEMG Ubá, 2008.

OLIVEIRA, J. E. Z. et al. Plantas medicinais: guia terapêutico. Viçosa: UFV, DFT, 2013.

ORGANIZAÇÃO MUNDIAL DE SAÚDE. Conselho Executivo. Medicina tradicional y asistencia sanitaria moderna. Foro Mundial de la Salud. Revista Internacional de Desarrollo Sanitario, [s.I.], v. 12 , n. 1 , p. 120, 1991.

ROSÁRIO-UBÁ, P. S. A. P.; OLIVEIRA, J. E. Z.; ARRUDA, V. M. Caderno do método biodigital. Viçosa: DFT/FUNARBE/UFV, 2011.

SILVA, M. D. P. et al. Levantamento das plantas medicinais da comunidade Barra de Mamanguape, Rio Tinto, PB: resgatando e valorizando o saber. In: NOME DO EVENTO. DATA DO EVENTO, CIDADE DO EVENTO. Anais... [s.I.]: [s.n], [20??]. Disponível em: <www.prac.ufpb.br/anais/ XIIIENEX_XIVENID/ENEX/PROEX/completos_05.html>. Acesso em: 5 nov. 2012.

SILVA JÚNIOR, A.A. Plantas medicinais e aromáticas. Itajaí: Epagri, 1997. CD-ROM.

SIMÕES, C.M.O. et al. (Org.) Farmacognosia: da planta ao medicamento. 5 ed. Porto Alegre:

Editora Universidade UFRGS, Florianópolis: Editora UFSC, 2004.

\section{Histórico editorial}

Recebido: 07/01/2013

Avaliação e copidesque: 07/01/2013 a 13/06/2013 


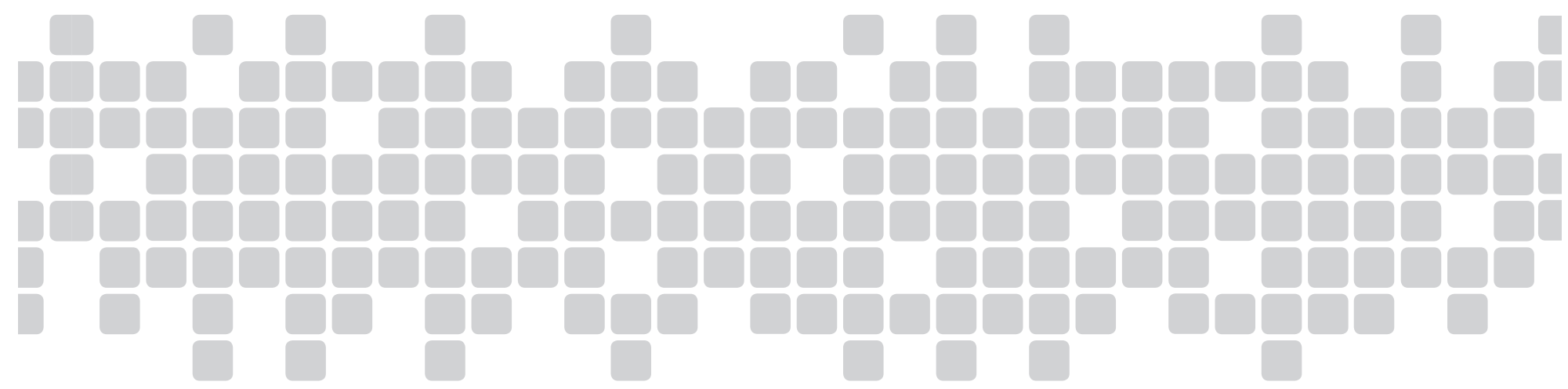

